\title{
Research on the Impact of Entrepreneurship Learning on Farmers' Entrepreneurship Performance
}

\section{Taking Entrepreneurial Ability as the Mediating Variable}

\author{
Ling Zhang ${ }^{1}$ Qinjuan $\mathrm{Li}^{2}{ }^{2 *}$ Shiyun Shao ${ }^{2}$ Yi Chen ${ }^{2}$ Tao Wang ${ }^{3}$ Hongliang Tian ${ }^{3}$ \\ Qing $\mathrm{Xu}^{2}$ Wenjie $\mathrm{Yao}^{2}$ \\ ${ }^{1}$ College of Law, Sichuan Agricultural University, Yaan, Sichuan, China \\ ${ }^{2}$ College of Humanities, Sichuan Agricultural University, Yaan, Sichuan, China \\ ${ }^{3}$ Department of Human Resource Management, The Third Construction Engineering Company LTD. of China \\ Construction Second Engineering Bureau, Beijing, China \\ *Corresponding author. Email: 1018784307@qq.com
}

\begin{abstract}
Through literature reading, this paper clarifies the concept of key research variables, establishes a research model, and explores the incentive mechanism of entrepreneurial learning on entrepreneurial performance and the mediating role of entrepreneurial ability in it. Through the descriptive analysis, correlation analysis, and regression analysis of the survey feedback data of 207 farmer entrepreneurs through spss, the research results show that: firstly, entrepreneurial learning has a significant positive impact on farmers' entrepreneurial ability; secondly, entrepreneurial learning has effects on farmers Entrepreneurship performance has a significant positive impact; thirdly, entrepreneurship ability also has a significant positive impact on entrepreneurship performance; forthly, entrepreneurship ability plays a complete mediating effect between entrepreneurial learning and entrepreneurial performance.
\end{abstract}

Keywords: Farmers' entrepreneurship, Entrepreneurial learning, Entrepreneurial ability, Entrepreneurial performance.

\section{INTRODUCTION}

With the achievement of a historic victory in the fight against poverty, the three-agriculture strategy has shifted to rural revitalization in an all-round way. The main goal and direction of rural revitalization is to develop rural industries, improve the rural economic structure, and make the rural richer... In the new era, how to adjust the rural economic structure, thrive rural industries, and increase farmers' income have become new issues for rural development. In the context of rural revitalization and encouragement of entrepreneurship, the number of farmers starting their own businesses has increased year by year. Farmers' entrepreneurship can fully make up for the weak links of rural industries, and it has become an important measure to promote the development of rural areas and realize the modernization of the economic system, and is the key to rural revitalization. The government attaches great importance to the prospects and development of farmers' entrepreneurship, and has issued a series of documents such as the "Opinions on Supporting Migrant Workers and Other People to Return to Their Hometowns to Start Businesses", "Opinions on Supporting the Entrepreneurship and Innovation of People Returning to the Country and Promoting the Integrated Development of Rural Primary, Secondary and Tertiary Industries", "Guiding Opinions of the State Council on Promoting the Revitalization of Rural Industries", "Opinions on accelerating the revitalization of rural talents", etc., which explicitly encourage farmers, returning rural migrant workers and other talents to start businesses in their hometowns. Farmers' 
entrepreneurial activities have reached a climax. According to the latest statistics from the Ministry of Agriculture and Rural Affairs, in 2020, there will be 31.5 million innovative entrepreneurs in China's countryside, and 10.1 million returnees and entrepreneurs in rural areas.

However, a huge base does not mean comprehensive results. The current status of farmers' entrepreneurial performance is not optimistic. Wei Juan et al. (2021)[3] believe that farmers and migrant workers objectively have limitations from themselves and the outside world. Entrepreneurship, an action that inherently has this risk, will only intensify the risk, and the number of failures and consequences will be more serious. Farmer entrepreneurship is restricted by many factors such as personal characteristics, abilities, environment, resources, etc. Generally speaking, farmers still have the characteristics of low educational background, low technology integration, and insufficient original funds. Lu Huiming and Wang Yanan (2021) [1] believe that this characteristic will cause farmers to face more difficulties in entrepreneurship, which is ultimately manifested in the lower success rate and greater risk of farmers' entrepreneurship. In order to improve the entrepreneurial success rate and entrepreneurial performance of farmers, many scholars have studied farmers' entrepreneurship issues based on the environmental background of rural revitalization, and explored "new shortcuts" for farmers' entrepreneurship from the perspectives of training, financing, and entrepreneurship. How to improve the effect of entrepreneurial learning? Does entrepreneurial ability play a role? This paper takes "knowledge acquisition-ability improvementperformance growth" as the main line to explore the internal relationship between the three variables, which is conducive to enriching the research on entrepreneurial learning, entrepreneurial ability and entrepreneurial performance at the individual level. And improving farmers' entrepreneurial performance is of great significance to rural industrial construction and rural revitalization. Entrepreneurship learning, as an influencing factor of entrepreneurial performance, can make up for the lack of entrepreneurial ability caused by unstable entrepreneurial willingness, inactive motivation, poor training, etc., thereby improving entrepreneurial performance, and has certain practical significance for guiding farmers to practice entrepreneurial learning methods.

\section{LITERATURE REVIEW}

\subsection{The Relationship Between Entrepreneurial Learning, Entrepreneurial Ability, and Entrepreneurial Performance}

At present, the positive correlation between these three variables has been generally recognized. Minniti, Bygrave (2001) pointed out that entrepreneurial learning can improve entrepreneurs' abilities, prompt them to continuously update entrepreneurial knowledge, gradually correct and improve entrepreneurial strategies, and thereby enhance entrepreneurial performance, and promote the improvement and enhancement of enterprise performance. Through literature reading and actual investigation, it is not difficult to find that farmers' entrepreneurship is often an action that imitates the behavior of others to acquire knowledge and experience and is accompanied by the growth and improvement of ability. These observations, models, and communication behaviors will improve farmers' abilities. And abilities determine the behavioral effect in the entrepreneurial process, that is, performance.

\subsection{Literature Recitation}

The current research on entrepreneurial ability as an intermediary and entrepreneurial learning and entrepreneurial performance is still lacking. However, the research on the relationship between the three variables has gained some recognition. The three variables of entrepreneurial learning, entrepreneurial ability, and entrepreneurial performance have all appeared in various dimensions in the research process, and these studies are relatively concentrated on the organizational level. Especially for entrepreneurial learning, Zhu Xiumei et al. (2017) [5] found through a large number of literature studies that almost all current research stems from the interaction between entrepreneurship and organizational learning. The core concepts and scales of entrepreneurial learning are mainly borrowed from organizational learning. The theoretical system of entrepreneurial learning is extremely imperfect, which makes the development of entrepreneurial learning theory slow. However, there is little research on the mechanism of entrepreneurial ability as the mediating effect of entrepreneurial learning on entrepreneurial performance. And the current research on entrepreneurship is more concentrated on the level 
of enterprises and organizations, and less research on entrepreneurial performance at the level of farmers and individuals. This paper tends to focus entrepreneurial ability on more individual farmers who develop individual economic households, using return rate, goal achievement, personal satisfaction, and profit as the four indicators of performance to enrich the research background of entrepreneurial learning, entrepreneurial ability, and entrepreneurial performance.

\section{RESEARCH HYPOTHESIS AND RESEARCH MODEL}

\subsection{Research Hypothesis}

\subsubsection{Entrepreneurship Learning and Entrepreneurial Performance}

Start-ups and entrepreneurs often lack the two elements necessary to maintain the survival of the enterprise and gain competitive advantage - the knowledge and ability to survive and the ability to innovate. Fortunately, these two necessary conditions can be obtained through entrepreneurial learning. Zhang Wenwei (2017)[5] pointed out that entrepreneurial learning can better help companies achieve goals, meet customer needs, and provide better services in adapting to the environment. It can also promote the establishment of learning organizations, allow knowledge to be spread and accumulated within the enterprise, form unique capabilities and competitive advantages, and promote performance improvement. To a large extent, the ability to deal with risks improved by entrepreneurial learning can effectively hedge risks, improve the survival rate of enterprises, help enterprises gain competitive advantages in the market, provide high-quality products and services, and gain customer recognition, confidence and benefits. On the one hand, in order to survive or maintain a competitive advantage, enterprises must maintain advanced knowledge reserves. This is also one of the manifestations of entrepreneurial performance. Knowledge is constantly developing and progressing. Therefore, if they want to have good entrepreneurial performance, their entrepreneurial learning cannot stop moving forward. On the other hand, innovation, as the core of a enterprise's competitive advantage, requires huge knowledge support, a wide range of fields, and a deep integration of old and new knowledge in order to maintain its survival advantage and competitive advantage for a long time. Therefore, the inquiry-based and utilization-based learning behaviors can just meet the requirements for the breadth and depth of knowledge for the improvement of entrepreneurial performance. Based on the above analysis, this paper proposes the following hypothesis:

H1: Entrepreneurship learning has a positive impact on the entrepreneurial performance of farmer entrepreneurs.

\subsubsection{Entrepreneurship Learning and Entrepreneurial Ability}

Entrepreneurship ability is a concentrated manifestation of personal characteristics in the factors affecting entrepreneurial performance, and its improvement is a dynamic and complex process. Entrepreneurship is the key to whether the resource base can be transformed into a competitive advantage. On the whole, existing studies agree that entrepreneurship is novel and useful, and requires continuous learning to stimulate its development. In the process of the leap from low to high level of entrepreneurial ability, there are huge differences in the characteristics and systems of these different knowledge stages at different stages of the ability development of each indicator, and they should correspond to a relatively clear learning system. Entrepreneurship learning theory is very helpful to show that learning behaviors can increase personal knowledge reserve and knowledge utilization rate. Entrepreneurship learning is continuous and longterm through observation, communication, training, and data collection. Entrepreneurship learning often occurs in entrepreneurial behavior. Foreign scholar Christensen (1997) Man (2002) and Chinese scholar Li Wen et al. (2016) divided entrepreneurial ability into opportunity identification ability and resource utilization ability, and pointed out that entrepreneurship learning has a great role in promoting the advantages of entrepreneurial innovation brought about by personal knowledge spillover. A large number of studies have shown that entrepreneurial learning has a significant positive effect on improving entrepreneurial capabilities by acquiring external knowledge and information and integrating this knowledge and information. Entrepreneurship learning gives farmers the ability to survive and earn returns during the entrepreneurial process. Based on the above analysis, this paper proposes the following hypothesis: 
$\mathrm{H}$ 2: Entrepreneurship learning has a positive impact on the improvement of the entrepreneurial ability of farmer entrepreneurs.

\subsubsection{Entrepreneurial Ability and Entrepreneurial Performance}

Yao Tianhan (2019)[4] regards input and output as the basic manifestation of entrepreneurial performance, reflecting the entrepreneur's ability to integrate and utilize resources, indicating that performance can be regarded as a concentrated expression of resource utilization ability in a certain aspect; Ma Hongyu (2016) explores whether entrepreneurial goals are achieved through entrepreneurial ability and whether entrepreneurial activities are effective, and determine the important role of entrepreneurial ability in accordance with the principles of survival performance and successful performance. Entrepreneurship ability is an important influencing factor of entrepreneurial performance, and there has been relatively complete research. Entrepreneurship ability ensures that farmers have the basic conditions to maintain the survival of the enterprise in the process of entrepreneurial behavior, and ensure that farmers' entrepreneurial activities can obtain substantial returns. Based on the above analysis, this paper proposes the following hypothesis:

H3: The improvement of entrepreneurial ability has a positive impact on the improvement of entrepreneurial performance.

\subsubsection{The Mediating Role of Entrepreneurial Ability}

Lv Huiming (2021)[1] stated that whether farmers can start their own business through the risks and their own limitations to achieve good entrepreneurial performance depends not only on the grasp and use of resources, but also on the conversion of resources to performance. However, the ability to realize the smooth transformation of resources depends on the level of entrepreneurial ability of the enterprise. It is pointed out that although a large number of studies have verified that entrepreneurial learning can have a positive impact on farmers' entrepreneurship. Since entrepreneurial performance is the result of entrepreneurial behavior in a specific environment, learning behavior is not entrepreneurial behavior in the entrepreneurial process. Since learning is not directly involved in entrepreneurial behavior, it plays a direct and indirect role in influencing entrepreneurial performance. Based on the above analysis, this paper proposes the following hypothesis:

H4: Entrepreneurial ability plays a mediating role in the effect of entrepreneurial learning on entrepreneurial performance.

\subsection{Research Model}

According to the above assumptions, we build a research model based on "entrepreneurial learningentrepreneurial ability-entrepreneurial performance". The theoretical model is as follows ("Figure 1"):

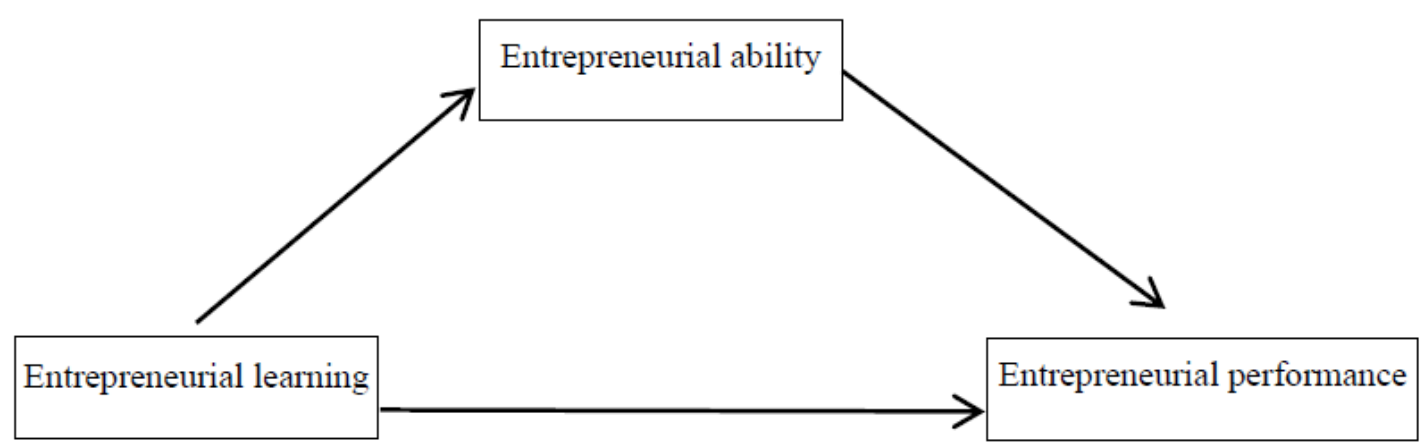

Figure 1 "Learning-ability-performance" theoretical model. 


\section{RESEARCH METHODS}

\subsection{Research Tools}

\subsubsection{Background information}

The background information mainly collects information on the interviewee's gender, age, education, whether he/she has been engaged in entrepreneurial activities, whether he/she has work experience in related industries, and whether he/she has participated in entrepreneurial-related training. questions based on pre-defined indicators.

\subsubsection{Scales}

The measurement questionnaire of the variables involved in this research refers to mature scales in China and foreign countries, using Likert's fivepoint scoring method, 1 means "completely disagree" and 5 means "completely agree". The higher score it gets, the more significant it is.

Entrepreneurship learning is the process of being able to grasp learning opportunities, obtain information and knowledge through various means, break the rigid thinking and have the ability to apply knowledge to create value. Referring to the existing scales, the researchers design 10 item scales, covering the three dimensions of observation, model, and communication.

Entrepreneurship ability is the collection of a series of technologies, knowledge and abilities that are beneficial to the success of the enterprise. According to the definition of the concept, 16 questions were set, covering the ability to identify opportunities and the ability to use resources, as well as the personal characteristics required for successful entrepreneurship.

Entrepreneurship performance measures farmers' entrepreneurial performance from five dimensions: return RTE, goal achievement, personal satisfaction, profit, and sales. 5 items are designed with reference to the existing scales.

The Kronbach's $\alpha$ coefficient of the scale is 0.907 , the KMO is 0.634 , and the significance of the Bartlett spherical test result is 0.000

\section{DESCRIPTIVE ANALYSIS RESULTS AND DISCUSSION}

\subsection{Research Sample}

This questionnaire survey mainly selected members from the surrounding areas of Ya'an and Sichuan Province Returning Home Entrepreneurship Alliance as the research objects. A total of 329 questionnaires were issued and 207 were effectively recovered. The response rate of questionnaires was $62.92 \%$. The researchers mainly use statistical software such as SPSS and Excel for data processing. The specific sample distribution is shown in "Table 2":

Table 1. Overall scores of variables

\begin{tabular}{|c|c|c|c|c|c|}
\hline & & Minimum value & Maximum value & Mean value & $\begin{array}{l}\text { Standard } \\
\text { deviation }\end{array}$ \\
\hline $\begin{array}{l}\text { Entrepreneurial } \\
\text { performance }\end{array}$ & 207 & 1.00 & 5.00 & 3.2600 & .75096 \\
\hline Entrepreneurial ability & 207 & 2.00 & 5.00 & 3.7728 & .54689 \\
\hline $\begin{array}{l}\text { Entrepreneurial learning } \\
\text { Number of active case } \\
\text { (column) }\end{array}$ & $\begin{array}{l}207 \\
S_{2} \\
207\end{array}$ & 2.00 & 5.00 & 3.8158 & 62379 \\
\hline
\end{tabular}

Table 2. Sample feature distribution

\begin{tabular}{|c|c|c|c|c|c|c|c|}
\hline & Item & $\begin{array}{l}\text { Sample } \\
\text { size }\end{array}$ & Proportion & Variables & Item & $\begin{array}{l}\text { Sample } \\
\text { size }\end{array}$ & Proportion \\
\hline \multirow{3}{*}{ Gender } & Male & 153 & $73.91 \%$ & & $\begin{array}{l}\text { Junior high school } \\
\text { and below }\end{array}$ & 20 & $9.66 \%$ \\
\hline & Female & 54 & $26.09 \%$ & $\begin{array}{l}\text { Education } \\
\text { background }\end{array}$ & $\begin{array}{l}\text { Senior high school / } \\
\text { technical secondary } \\
\text { school / technical } \\
\text { school }\end{array}$ & 98 & $47.34 \%$ \\
\hline & $\begin{array}{l}25 \text { years old } \\
\text { and under }\end{array}$ & 9 & $4.35 \%$ & & Junior college & 65 & $31.40 \%$ \\
\hline \multirow{2}{*}{ Age } & $26-30$ years old & 34 & $16.43 \%$ & & Bachelor or above & 24 & $11.59 \%$ \\
\hline & $31-35$ years old & 39 & $18.84 \%$ & $\begin{array}{l}\text { Working } \\
\text { experience } \\
\text { industry } \\
\end{array}$ & in Yes & 117 & $56.52 \%$ \\
\hline
\end{tabular}




\begin{tabular}{|c|c|c|c|c|c|c|c|}
\hline & Item & $\begin{array}{l}\text { Sample } \\
\text { size }\end{array}$ & Proportion & Variables & Item & $\begin{array}{c}\text { Sample } \\
\text { size }\end{array}$ & Proportion \\
\hline \multirow{3}{*}{ Age } & $36-40$ years old & 35 & $16.91 \%$ & $\begin{array}{l}\text { Working } \\
\text { experience } \\
\text { industry }\end{array}$ & in No & 90 & $43.48 \%$ \\
\hline & $41-50$ years old & 80 & $38.64 \%$ & \multirow[b]{2}{*}{ Training } & Yes & 119 & $57.48 \%$ \\
\hline & $\begin{array}{l}51 \text { years old } \\
\text { and above }\end{array}$ & 10 & $4.83 \%$ & & No & 88 & $42.51 \%$ \\
\hline \multirow{2}{*}{$\begin{array}{l}\text { Venture } \\
\text { development } \\
\text { experiences }\end{array}$} & Yes & 137 & $66.18 \%$ & & & & \\
\hline & No & 70 & $33.82 \%$ & & & & \\
\hline
\end{tabular}

"Table 2" covers the basic evaluation rate analysis of the six dimensions of gender, age group, education background, entrepreneurial experience, industry work experience, and training. From the perspective of demographic characteristics, the gender ratio of farmers in entrepreneurship is heavily biased. The ratio of male entrepreneurs to entrepreneurship is $73.91 \%$, which is much higher than that of females at $26.09 \%$. The distribution of age groups is relatively even, except that people aged 41-50 years old account for as much as $38.64 \%$, and those under 25 years old and over 51 years old account for only about $4 \%$.

From the perspective of education background, only a very small number of peasant entrepreneurs have a bachelor degree or above. Junior college degree or below accounted for more than $50 \%$. In terms of entrepreneurial experience, most peasant entrepreneurs have started their own businesses for the second time or more, and those with entrepreneurial experience accounted for $66.18 \%$. The distribution of the number of people from the two dimensions of industry work experience and participation in training tends to be even.

\subsection{Descriptive Analysis}

under the background of rural revitalization, the average values of farmers' entrepreneurial performance, entrepreneurial ability, and entrepreneurial learning scores are 3.2600, 3.7728, and 3.8158 , respectively, and the average values are all biased towards the maximum value of 5 , indicating that farmers' entrepreneurial learning, entrepreneurial ability and entrepreneurial performance are all relatively high

In order to explore whether there are differences in personal characteristics among the three variables, a descriptive analysis of entrepreneurial learning, entrepreneurial ability, entrepreneurial performance in terms of gender, age group, etc.is obtained .
The scores of the three variables related to entrepreneurship in this paper have certain differences between genders. The average score of men is about 0.2 points higher than that of women.

And it also has a large difference in age, with a range of about 0.4 . The scores in learning, ability, and performance are relatively high at the 26-30 year old stage and the 36-40 year old stage.

And when it is for educational degree there's a range of about 0.25 . Entrepreneurs with a high school/technical secondary school/technical school degree have higher scores in learning, ability, and performance than those with a higher education background. It is the group with the highest score among the four academic stages.

About the entrepreneurial experience, the average values of entrepreneurial learning, ability and performance scores of entrepreneurs with entrepreneurial experience are 3.87, 3.83 and 3.30. These all higher than those of entrepreneurs without entrepreneurial experience which are 3.17, 3.18 and 3.66 .

And there are certain differences in whether they have industry work experience. The average value of entrepreneurial learning, ability and performance scores of farmer entrepreneurs with industry work experience are 3.88, 3.41 and 3.78 . These all higher than those of entrepreneurs without industry work experience which are $3.74,3.07$ and 3.76 .

And it is different in terms of whether to participate in training. The average values of entrepreneurial learning, ability and performance scores of farmers participating in training are 3.89, 3.38 and 3.85. These all higher than those of entrepreneurs not participating in training which are $3.72,3.10$ and 3.67 . 


\subsection{Discussion of the Results of Descriptive Analysis}

\subsubsection{The Three Main Variables Show the Same Trend Under the Influence of the Same Control Variable}

According to the descriptive analysis, the average scores of entrepreneurial learning, entrepreneurial ability, and entrepreneurial performance in the six aspects of gender, age, education, entrepreneurial experience, industry work experience, and training all show the same trend. Both high scores and low scores are concentrated in certain personal traits, which can initially reflect that entrepreneurial learning, entrepreneurial ability, and entrepreneurial performance may have a positive correlation.

According to the regression analysis of the control variables introduced in "Table 4", whether the six control variables have industry work experience has significant regression effects in the four models, indicating whether or not industry experience has a significant positive impact on entrepreneurial performance. According to the interviewee's statement, the industry work experience greatly affects the familiarity of industry rules and industry knowledge, and this familiarity comes from the experience accumulated through observation, model, communication and other learning behaviors in the process of industry work experience. To a certain extent, industry work is the advancement of entrepreneurial learning learning in industry work is invisibly produced through the initiative and passiveness, which can quickly increase industry knowledge reserves, and work behavior is the continuous use of existing knowledge.

\subsubsection{The Educational Background and Other Limitations of Farmers and Entrepreneurs Are Relatively Prominent}

Through the distribution of the sample characteristics in "Table 2" and the overall score analysis of the variables in "Table 1", it can be found that entrepreneurial farmers' academic qualifications are more limited - only $11.59 \%$ of farmer entrepreneurs have a bachelor's degree or above, which leads to the lack of knowledge support for most farmer entrepreneurs in the initial stage of entrepreneurship, making them more likely to face their own limitations during the entrepreneurial process and need to learn to help cope with difficulties and risks. The second is the limitation caused by age differences: $38.64 \%$ of farmers are entrepreneurs from 41 to 50 years old, which is the highest proportion among several age groups. Farmer entrepreneurs over 40 account for $43.47 \%$, compared to the current other two more broad entrepreneurial groups - college students and veterans, farmer entrepreneurs are older. Although studies have shown that rising age has a positive impact on personal experience, it also has a negative impact on personal energy, passion, and learning ability. These characteristics all show that farmers entrepreneurs have their own entrepreneurial limitations that other groups do not possess. Moreover, the proportion of peasant entrepreneurs who start their own businesses again is as high as $66.18 \%$, which also reflects the fact that the survival and success rate of farmers' entrepreneurship is not high.

\subsubsection{Highly Educated Farmer Entrepreneurs Have Low Performance}

What is more special is that entrepreneurs under the age of 25 who are at the peak of learning ability and experience have the lowest three-variable scores for entrepreneurship. Ma Lan (2020)[2] stated that college graduates will increase their entrepreneurial failure rate due to insufficient resources in the early stages of entrepreneurship. Farmer entrepreneurs under the age of 25 also face the same problem. The youth and the lack of knowledge reserves, experience and resources caused by youth will increase the risk of farmers' entrepreneurship and reduce the survival performance of enterprises. The three-variable scores of farmer entrepreneurs with junior college and undergraduate education levels are lower than those with high school/technical secondary school/technical school level, and the scores continue to decrease as their education level rises. After interviews with some farmers' entrepreneurs, it is found that there may be two main reasons for the lower entrepreneurial performance of those with high academic qualifications: one is that the knowledge of academic learning is not sufficiently utilized in entrepreneurial behavior, which means that the degree of utilization learning in entrepreneurial learning behavior is low; the other is that those with higher educational backgrounds are younger and have insufficient resource experience. 


\section{CORRELATION ANALYSIS, REGRESSION ANALYSIS RESULTS AND DISCUSSION}

\subsection{Correlation Analysis}

In order to analyze the influence relationship between variables and measure the strength of the

Table 3. Mean value, standard deviation and correlation coefficient of each variable phase

\begin{tabular}{|c|c|c|c|c|c|}
\hline Variables & Mean value & $\begin{array}{l}\text { Standard } \\
\text { deviation }\end{array}$ & $\begin{array}{c}\text { Entrepreneurial } \\
\text { learning }\end{array}$ & $\begin{array}{c}\text { Entrepreneurial } \\
\text { ability }\end{array}$ & $\begin{array}{c}\text { Entrepreneurial } \\
\text { performance }\end{array}$ \\
\hline $\begin{array}{l}\text { Entrepreneurial } \\
\text { learning }\end{array}$ & 3.8158 & 0.62379 & 0.858 & & \\
\hline $\begin{array}{l}\text { Entrepreneurial } \\
\text { ability }\end{array}$ & 3.7728 & 0.54689 & $0.577^{\star *}$ & 0.892 & \\
\hline $\begin{array}{l}\text { Entrepreneurial } \\
\text { performance }\end{array}$ & 3.2600 & 0.75096 & $0.343^{\star *}$ & $0.478^{* *}$ & 0.860 \\
\hline
\end{tabular}

From "Table 3", under the condition of a significance level of 0.01 , the Pearson correlation coefficient between entrepreneurial learning and entrepreneurial ability is 0.577 , indicating a positive correlation between the two; the Pearson correlation coefficient between entrepreneurial learning and entrepreneurial performance is 0.343 , indicating that there is a positive correlation between the two; the Pearson correlation coefficient of entrepreneurial ability and entrepreneurial performance is 0.478 , indicating that there is a positive correlation between the two. Through the above three correlation analysis, it can be seen that the three hypotheses $\mathrm{H} 1, \mathrm{H} 2$, and $\mathrm{H} 3$ proposed in the previous content have all been verified.

\subsection{Regression Analysis}

Model 1 in "Table 4" is the result of using entrepreneurial performance as a dependent variable and gender, age, educational background, entrepreneurial experience, industry work relationship, the Pearson correlation coefficient is analyzed and calculated to obtain the results in the following "Table 3 ".

Table 4. Variable regression analysis

\begin{tabular}{|c|c|c|c|c|}
\hline \multirow{2}{*}{ Variables } & \multicolumn{3}{|c|}{ Entrepreneurial performance } & \multirow{2}{*}{$\begin{array}{c}\text { Entrepreneurial ability } \\
\text { Model } 4\end{array}$} \\
\hline & Model 1 & Model 2 & Model 3 & \\
\hline \multicolumn{5}{|l|}{ Control variable } \\
\hline Gender & 0.013 & -0.027 & -0.040 & 0.030 \\
\hline Age & -0.050 & -0.009 & -0.002 & -0.015 \\
\hline Education background & -0.109 & 0.062 & -0.074 & 0.028 \\
\hline Venture development experiences & -0.007 & -0.040 & -0.073 & 0.075 \\
\hline Industry work experience & $0.187^{\star}$ & $0.171^{* *}$ & $0.213^{\star \star}$ & -0.096 \\
\hline Training & 0.133 & 0.108 & & \\
\hline \multicolumn{5}{|l|}{ Independent variable } \\
\hline Entrepreneurial learning & & $0.310^{* *}$ & & \\
\hline \multicolumn{5}{|l|}{ Mediating effect } \\
\hline Entrepreneurial learning & & & 0.062 & $0.566^{\star \star}$ \\
\hline Entrepreneurial ability & & & $0.439^{\star *}$ & \\
\hline
\end{tabular}


It can be seen from "Table 4" that entrepreneurial learning has a significant positive impact on entrepreneurial performance (Model 2: regression coefficient $\beta=0.310, p<0.01)$, and entrepreneurial learning also has a significant positive impact on entrepreneurial ability (Model 4: regression coefficient $\quad \beta=0.566, \quad \mathrm{p}<0.01$ ). Introducing entrepreneurial ability into the regression analysis of entrepreneurial learning and entrepreneurial performance, it is concluded that the regression coefficient of entrepreneurial ability to entrepreneurial performance is significant (Model 3: regression coefficient $\beta=0.439, \mathrm{p}<0.01$ ). Therefore, the mediating effect of entrepreneurial ability between entrepreneurial learning and entrepreneurial performance has been verified, that is, the mediating effect is significant. With the introduction of the mediation effect, the regression coefficient of entrepreneurial learning on entrepreneurial performance is not significant (model 3: regression coefficient $\beta=0.062 . p>0.01$ ), so it is a complete mediating effect. It can be seen that the three hypotheses and $\mathrm{H} 4$ proposed in the previous article have all been verified.

\subsection{Discussion on the Results of Correlation and Regression Analysis}

\subsubsection{The Mechanism of Entrepreneurial Learning on Entrepreneurial Performance}

This paper uses literature reading as the theoretical and logical starting point for this research and proposes research hypotheses. The hypotheses are verified by mathematical analysis of
207 questionnaires about farmers' entrepreneurship. On the basis of the above-mentioned theory, the assumptions $\mathrm{H} 1, \mathrm{H} 2, \mathrm{H} 3$, and $\mathrm{H} 4$ are all verified through regression analysis.

Entrepreneurship learning is not a part of entrepreneurial behavior, and entrepreneurial behavior is the core factor that results in entrepreneurial performance. Although learning is used as a preliminary preparation for entrepreneurial behavior or the behavior of "learning by doing" leads to simultaneous entrepreneurial learning and entrepreneurial behavior, learning cannot be directly summarized as direct behavior for obtaining entrepreneurial results, so entrepreneurship learning does not directly affect entrepreneurial performance, but requires an intermediate influencing factor. It has been verified that entrepreneurial ability can be used as this factor.

\subsubsection{Revision of Research Model}

The three main research objects in this paper all have significant correlations. As a mediating variable, entrepreneurial ability has a significant mediating effect, indicating that entrepreneurial ability plays a mediating role between entrepreneurial learning and entrepreneurial performance, and is a complete mediating relationship. This shows that entrepreneurial learning does not directly affect entrepreneurial performance, but instead plays a cohesive role in the middle through entrepreneurial ability. This means that the theoretical model proposed in the previous article needs to be revised. The revised results are as follows ("Figure 2").

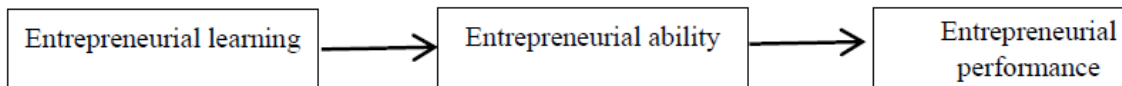

Figure 2 Revision of research model.

\section{CONCLUSION AND SUGGESTIONS}

\subsection{Conclusion}

With the deepening of research on entrepreneurial performance, the interactive influence of entrepreneurial performance has been widely recognized. Performance is not determined by a single factor, but by many influencing factors. At present, the most widely recognized influencing factors are roughly divided into five categories: subjective and objective, environmental factors, resource support, strategic factors, entrepreneurs and their teams, and other factors. Subjective factors are mainly the personal characteristics of entrepreneurs, while objective factors include environmental factors such as external policies and resources. These influencing factors will affect the changes of entrepreneurial performance indicators under a specific mechanism, and thus affect entrepreneurial performance. The continuous deepening of entrepreneurial learning urges farmers to continuously explore their entrepreneurial 
abilities and enhance their entrepreneurial capabilities, thereby forming high-quality personal traits, and helping to form heterogeneous resource advantages for farmers' entrepreneurs, to play a good role in promoting entrepreneurial performance. Entrepreneurship ability plays an important role as a bridge between entrepreneurial learning and entrepreneurial performance. As the rural industry develops into building a new type of countryside and promoting rural development, improving farmers' entrepreneurial survival and successful performance will play a vital role in the process of rural industry enrichment. Entrepreneurship learning and entrepreneurial ability are fully positive influence factors on entrepreneurial performance. People can stimulate the growth of entrepreneurial performance by improving the effect of entrepreneurial learning.

\subsection{Suggestions}

This paper starts from the two dimensions of government and farmer entrepreneurs, and puts forward the following suggestions:

\subsubsection{Promoting the Adaptation of Entrepreneurial Learning Behavior and Learning Stage}

In the dual learning theory, two methods of exploratory learning and utilization learning have been proposed. These two learning modes increase the breadth of knowledge and the familiarity of knowledge. This theoretical perspective gave the researchers a way to improve the learning effect of farmers' entrepreneurship. The breadth and depth of knowledge promote each other under specific conditions, and adjust the two learning focuses according to different conditions, save learning energy and improve learning efficiency. As for the entrepreneurial group of farmers, due to the relative lack of basic knowledge reserves, exploratory learning can increase their knowledge reserves in a short period of time. However, at the same time, because farmers' entrepreneurship requires short payback periods and fast returns, farmers cannot continue to carry out exploratory learning with high intensity for a long time. After they have a certain amount of knowledge, the use of highly utilized learning can improve entrepreneurial performance in the short term, but to realize the sustainable development of enterprises, they still need to rely on exploratory learning. Due to the limited energy of individuals and teams at a given time, it is not realistic to require everyone to maintain a high degree of exploratory and utilization learning for a long time. Combining with the outstanding status quo of farmers' "learning by doing", entrepreneurial individuals use existing knowledge while conducting exploratory learning, and continuously improving existing behavior patterns to achieve the goal of improving performance is the most ideal result.

When conducting training courses, the government can adjust the training content according to the type and stage of entrepreneurship of the trainee, so as to save entrepreneurs' entrepreneurial experience.

Entrepreneurs should combine their own characteristics with the needs of the entrepreneurial stage, and promote the interlacing of exploratory learning and utilization learning, which will help rationally allocate energy and improve performance.

\subsubsection{Promoting the Development of Farmer Entrepreneurship Training System}

In this era of knowledge economy, the development of enterprises depends more on the accumulation and application of entrepreneurial knowledge, and the best way to obtain entrepreneurial knowledge is entrepreneurial learning. And training is an effective means to effectively improve the evaluation rate and effectiveness of farmers' entrepreneurial learning through changes in the external environment. Since farmers are more prone to entrepreneurship, their own defects are more prone to "new entrant disadvantages", and their need to overcome the "new entrant disadvantages" through the accumulation of entrepreneurial knowledge is more urgent. Training can help to do this, so that new enterprises can better build dynamic competitive advantages and achieve sustainable development. Due to various environmental constraints, the phenomenon of "learning by doing" for farmers to start a business is prominent. It is even more important to use training to help individuals identify, accumulate and create entrepreneurial experience and knowledge. At present, the way that farmers and entrepreneurs obtain external knowledge and advanced experience has been improved more than before, and the rise of the Internet has broken the space and time limitations of knowledge. However, the training system for farmers' entrepreneurship is not comprehensive and complete. Improving the popularity and pertinence of farmers' entrepreneurship training is more 
conducive to the success of farmers' entrepreneurship.

\subsubsection{Entrepreneurs Should Improve Their Entrepreneurial Mentality}

In view of the low level of entrepreneurial performance of high-educated entrepreneurs, through interviews to understand the subjective and objective reasons, it can be found that higheducated entrepreneurs have their entrepreneurial advantages in the early stage of entrepreneurship compared with other entrepreneurs-they have a broader knowledge reserve. The disadvantage is that the depth of exploitative learning is not enough, and the advantages of storing knowledge are not fully utilized. At the same time, high-educated people are prone to be relatively impetuous in the process of starting a business, hoping to get rewards as soon as possible, and not paying attention to learning and training. But in fact, it is difficult for an individual's existing knowledge and abilities to meet the needs of achieving entrepreneurial performance, and continuous learning is still needed to combat the difficulties in the entrepreneurial process. Entrepreneurs need to adjust their mentality in the entrepreneurial process and take entrepreneurial learning seriously to improve their entrepreneurial ability to achieve the goal of entrepreneurial performance growth.

\subsubsection{Continuing to Promote the Entry of High-quality Entrepreneurs into the Countryside}

According to the guidance of the "Opinions on Accelerating the Promotion of Rural Talent Revitalization", rural revitalization cannot be separated from talent revitalization. There are two directions for talent revitalization-making good use of existing rural human resources and introducing human resources from outside. At the same time, the existing data also show that the development of rural industries requires leading enterprises and leaders, which shows that high-quality entrepreneurs can greatly promote the development of rural industries. The government should insist on promoting and guiding college students to enter the countryside, and high-quality migrant workers return to school to start businesses, and promote the development of the entire rural entrepreneurial industry.

\section{AUTHORS' CONTRIBUTIONS}

Ling Zhang is responsible for compiling and editing the paper. Qinjuan $\mathrm{Li}$ contributed to compiling the paper. Shiyun Shao did the data analysis. Yi Chen is responsible for the literature review. Tao Wang contributed to software collation data. Hongliang Tian also contributed to software collation data. Qing Xu did the data collection. Wenjie Yao is also responsible for the date collection.

\section{REFERENCES}

[1] Lv Huiming, Wang Ya'nan, The Influence of Social Network on the Entrepreneurial Performance of Migrant Workers from the Perspective of the Intermediary Role of Entrepreneurial Ability [J]. Jounal of Ningbo University, 2021, 34(01): 95-102. (in Chinese)

[2] Ma Lan, Ru Dongyan, Xin Baoluo, Research on the Effect of Entrepreneurial Abilityfrom Ethnic-Minority University Students - Based on the Perspective of Entrepreneurial Learning [J]. Journal of Technical Economics \& Management, 2020(05): 25-32. (in Chinese)

[3] Wang Zhuandi, Ma Hongyu, Guo Pengyu, Entrepreneurial Passion, Entrepreneurial Learning and Entrepreneurial Performance of Migrant Workers [J]. South China Journal of Economics, 2020(05): 111-126. (in Chinese)

[4] Wei Juan, Zhao Jiajia, Liu Tianjun, Entrepreneurial Failures Do Not Always Lead to Subsequent Success: Evidence from Rural Chinese Entrepreneurs [J]. Studies in Science of Science, 2021, 39(02): 285-294. (in Chinese)

[5] on the Relationship Between Motivation of Intrapreneurship, Entrepreneurial Learning and Entrepreneurial Performance [D]. Nanjing University of Posts and Telecommunications, 2020. (in Chinese)

[6] Zhu Honggen, Liang Xi, Farmers' Entrepreneurial Motivation and Its Impact on Entrepreneurial Performance [J]. Journal of Agro-Forestry Economics and Management, 2017, 16(05): 643-651. (in Chinese) 